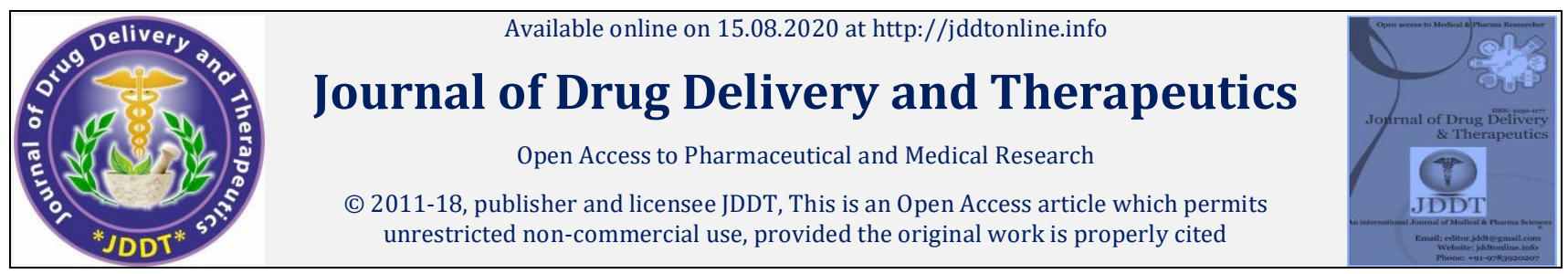

Open $\odot$ Access

Research Article

\title{
Formulation, Development and Evaluation of Uncoated Bilayer Tablet of Anti-Hypertensive Agents
}

\author{
* Kunjan Gandhi, Sunil Kumar Shah, C K Tyagi, Prabhakar Budholiya, Harish Pandey \\ Department of Pharmaceutics, College of Pharmacy, Sri Satya Sai University of Technology \& Medical Sciences, Sehore, Madhya Pradesh, India
}

\begin{abstract}
The present research work was carried out to Formulate and evaluation of bilayer tablet dosage form for the treatment of Hypertension.The objective of this study to compare the specific characteristics of Metoprolol [beta selective (cardio selective) adrenoreceptor blocking agent] and Hydrochlorothiazide (Thiazide Diuretics]) in order to design stable formulation. It can be concluded that bilayer tablet were successfully formulated to achieve immediate release of Hydrochlorothiazide (HCTZ) and tailored release of Metoprolol (MPL)by using Dual Release Drug Absorption System(DUREDAS technology).Both drugs were found to be stable in Bilayer tablet formulation and were found to be stable for few months. This bilayer tablet dosage form increases the stability which may reduce loss and cost of formulation. It improves the benefits of producer, retailer, and patients. Recently, greater attention has been focused on development of bilayer tablet formulations. Over the past 30 years, the expenses and complications involved in marketing new drug entities have increased with concomitant recognition of therapeutic advantages of conventional drug delivery system. Several pharmaceutical companies are currently developing bi-layer tablets, for a variety of reasons: patent extension, efficient pharmacological effect, better patient compliance, etc. Bilayer tablet is becoming new approach for the successful drug delivery system and for better stability in combination. Bilayer tablets can be primary option to avoid chemical incompatibilities between APIs by physical separation.
\end{abstract}

Keywords: Bilayer tablet, DUREDAS Technology, Antihypertensive, Metoprolol, Hydrochlorthiazide

Article Info: Received 17 June 2020; Review Completed 21 July 2020; Accepted 29 July 2020; Available online 15 August 2020

Cite this article as:

Gandhi K, Shah SK, Tyagi CK, Budholiya P, Pandey H, Formulation, Development and Evaluation of Uncoated Bilayer Tablet of Anti-Hypertensive Agents, Journal of Drug Delivery and Therapeutics. 2020; 10(4-s):100-107

http://dx.doi.org/10.22270/jddt.v10i4-s.4229

*Address for Correspondence:

Kunjan Gandhi, Department of Pharmaceutics, College of Pharmacy, Sri Satya Sai University of Technology \& Medical Sciences, Sehore, Madhya Pradesh, India

\section{INTRODUCTION}

Tablets may be defined as solid pharmaceutical dosage form containing drug substances with or without suitable diluents and prepared by either compression or molding method. ${ }^{1}$ Some tablets are swallowed whole or after being chewed, some are dissolved or dispersion in water before administration and some are retained in mouth where the active ingredient is liberated completely. Bi-layer tablet which is made up of two distinct layers or discrete zones of granulation compressed together with the individual layers lying one on top of another. Bilayer tablets are generally prepared by compressing granules on to previously partially compressed granules.When two or more active pharmaceutical ingredients which are incompatible are needed to be administered simultaneously, the best option for the formulation pharmacist would be to formulate multilayered tablet. It consists of several different granulations that are compressed to form a single tablet composed of two or more layers and usually each layer being of different color to produce a distinctive looking tablet. Each layer is fed from separate feed frame with individual weight control. Dust extraction is essential during compression to avoid contamination. Therefore, each layer undergoes light compression as each component is laid down. This avoids intermixing of granules due to mechanical vibration. One of the components has to undergo double compression. A stress sensitive drug can be formulated as an inlay or tab in tab approach. ${ }^{2}$ Hypertension is characterized by elevation of diastolic blood pressure, abnormal cardiac output and increased peripheral vascular resistance. Hypertension has recently increased in incidence throughout the world. One third of the men and two fifth of women over 40 years of age and majority of men over 60 and women over 50 probably have hypertension. It is thought that the stresses of everyday life with a change in the dietary habits and lack of exercise has led to the increasing incidence of hypertension. Previously hypertension was predominant only in industrialized and developed countries. However, of late there has been a sudden increase in the number of cases in developing countries $^{3}$. The WHO has defined hypertension as a state in which systolic pressure is $150 \mathrm{~mm} \mathrm{Hg}$ or more and diastolic pressure is $95 \mathrm{~mm} \mathrm{Hg}$ or more. ${ }^{4}$ Hypertension can be classified as either essential (primary) or secondary. Essential hypertension indicates that no specific medical cause can be found to explain a patient's condition. 
Secondary hypertension indicates that the high blood pressure is a result of (i.e. secondary to) another condition, such as kidney disease or tumors (pheochromocytoma and paraganglioma). Persistent hypertension is one of the risk factors for strokes, heart attacks, heart failure and arterial aneurysm, and is a leading cause of chronic renal failure. Even moderate elevation of arterial blood pressure leads to shortened life expectancy. At severely high pressures, defined as mean arterial pressures $50 \%$ or more above average, a person can expect to live no more than a few years unless appropriately treated.5, 6 Since it is very difficult to achieve the ideal situation with monotherapy, attempts have been made to create a more ideal treatment for hypertension by combining complementary drugs in low doses. Dual Release Drug Absorption System (DUREDAS technology) is a bilayer tablet which can provide immediate or sustained release of two drugs or different release rates of the same drug in one dosage form. The tabletting process can provide an immediate-release granulate and a modified-release hydrophilic matrix complex as separate layers within the one tablet. The modified-release properties of the dosage form are provided by a combination of hydrophilic polymers. The DUREDAS system can easily be manipulated to allow incorporation of two controlled release formulations in the bilayer. Two different release rates can be achieved from each side. In this way greater prolongation of sustained release can be achieved. Typically an immediate release granulate is first compressed followed by the addition of a controlled release element which is compressed onto the initial tablet. This gives the characteristic bilayer effect to the final dosage form. A further extension of the DUREDAS technology is the production of controlled release combination dosage forms whereby two different drugs are incorporated into the different layers and drug release of each is controlled to maximize the therapeutic effect of the combination. Again both immediate release and controlled release combinations of the two drugs are possible. A number of combination products utilizing this technology approach have been evaluated. The DUREDAS technology was initially employed in the development of a number of OTC controlled release analgesics. In this case a rapid release of analgesic is necessary for a fast onset of therapeutic effect. Hence one layer of the tablets is formulated as an immediate release granulates. By contrast, the second layer of the tablet, through use of hydrophilic polymers, releases drug in a controlled manner. The controlled release is due to a combination of diffusion and erosion through the hydrophilic polymer matrix. ${ }^{7}$ The present experimental work relates to stable dual release pharmaceutical compositions used for the treatment of cardiovascular diseases like hypertension comprising combination of therapeutically effective amount of a synthetic beta selective (cardio selective) adrenoreceptor blocking agent and a synthetic thiazide diuretic in the form of an oral solid bilayered formulation and to a process for preparation thereof. The one component (or layer) of Metoprolol is provided with an extended / sustained release and another component (or layer) of Hydrochlorothiazide is provided with an immediate release action.

\section{MATERIALS AND METHODS}

\section{Materials}

Metoprolol Succinate was obtained as gift sample from Cipla Ltd., Mumbai, and Hydrochlorothiazide was obtained from
Alembic Pharmaceuticals Ltd, India as a gift sample. The samples of Micro Crystalline Cellulose, Hypromellose $(\mathrm{K} 100 \mathrm{M})$ and Hypromellose $(\mathrm{K} 15 \mathrm{M})$ were procured from Colorcon, Goa. Lactose Monohydrate, Sodium Starch Glycolate, Dibasic Calcium Phosphate (Anhydrous) and Magnesium Stearatewere collected from SD Fine Chemicals, Mumbai, India. Pre gelatinised Starch, Povidone K30, Brilliant Blue and Starch Purity 21 were purchased from Nice Chemie Pvt. Ltd., Mumbai, India.

\section{Methods}

\section{Preliminary Studies}

The drug substance (Active) was analyzed as per Pharmacopoeial specification (USP).

\section{Manufacturing procedure of sustained release Metoprolol part}

The required quantity of Metoprolol, microcrystalline cellulose 101, HPMC K100M and carbopol 71G were sifted through sieve \# 40 in geometric proportion and collected in rapid mixer granulator (RMG). Dry mixing was done in rapid mixer granulator for 10 minutes at $100 \mathrm{rpm}$. Binder solution was prepared by dissolving accurately weighed quantity of PVP K30 in isopropyl alcohol. Binder solution was slowly added into the dry mix in RMG for 5 minutes at $100 \mathrm{rpm}$ and then for 5 minutes at $205 \mathrm{rpm}$ impeller speed and at 1000 rpm chopper speed to get proper dough mass. Isopropyl alcohol was further added slowly and RMG was allowed to run for further 3 minutes until granulation end-point was achieved. Chopper was used to break the lumps of the wet mass towards the granulation end-point. Wet mass of step no. 4 was sifted through sieve \# 12 before drying. Wet granules were initially air dried for $10 \mathrm{~min}$. Granules were further dried in fluidized bed drier at temperature of about $55-60{ }^{\circ} \mathrm{C}$ until the loss on drying (LOD) was between 2-3\% $\mathrm{w} / \mathrm{w}\left(\right.$ at $85^{\circ} \mathrm{C}$ ). Dried granules were sifted through sieve \# 20. Relubrication of dried granules was carried out by sifting and blending process.

\section{Manufacturing procedure of immediate release hydrochlorothiazide part}

Accurately weighed quantity of Hydrochlorothiazide, lactose monohydrate IP, dibasic calcium phosphate (anhydrous), starch purity, sodium starch glycolate, brilliant blue and pregelatinized starch were sifted through sieve \# 40 in geometric proportion. This mixture was collected in rapid mixer granulator (RMG).Dry mixing was done in rapid mixer granulator for 10 minutes at $100 \mathrm{rpm}$. Here starch purity act as a dry binder so purified water $\left(45-55^{\circ} \mathrm{C}\right)$ was taken as a Binder solution. Binder solution was slowly added to dry mix in the RMG for 5 minutes at $100 \mathrm{rpm}$, then for 3 minutes at $200 \mathrm{rpm}$ of impeller speed and at $1000 \mathrm{rpm}$ of chopper speed to get proper dough mass. Granulating fluid was further added slowly and RMG was allowed to run for further 2 min until granulation end-point was achieved. Chopper was used to break the lumps of the wet mass towards the granulation end-point. Wet mass obtained at step no. 5 was sifted through sieve no. 12 before drying. Wet granules obtained at step no. 5 were initially air dried for 10 min. Granules were further dried in fluidized bed drier at temperature of about $55-60^{\circ} \mathrm{C}$ until the loss on drying (LOD) was between $2-3 \% \mathrm{w} / \mathrm{w}$ (at $105^{\circ} \mathrm{C}$ ). Dried granules were sifted through sieve no. 30.Lubrication of dried granules was carried out by sifting and blending method. Total six batches were prepared as shown in table 1 
Table 1: Formulation of Metoprolol Succinate and Hydrochlorthiazide

\begin{tabular}{|c|c|c|c|c|c|c|c|}
\hline \multirow{2}{*}{ Sr. No. } & \multirow{2}{*}{ Ingredients } & \multicolumn{6}{|c|}{ Qty. (mg/unit Dose } \\
\hline & & B1 & B2 & B3 & B4 & B5 & B6 \\
\hline \multicolumn{8}{|c|}{ Metoprolol Succinate part (sustained release) } \\
\hline 1 & Metoprolol Succinate & 23.41 & 23.41 & 23.41 & 23.41 & 23.41 & 23.41 \\
\hline 2 & Micro Crystalline Cellulose 101 & 46.35 & 24.16 & 18.16 & 14.16 & 24.16 & 14.16 \\
\hline 3 & HPMC K15M & 35 & 45 & 45 & 45 & - & - \\
\hline $\mathbf{3 A}$ & HPMC K100M & - & - & - & - & 50 & 50 \\
\hline 4 & Carbopol 71G & 17.81 & 19 & 22.5 & 25 & 25 & 30 \\
\hline 5 & PVP K30 & 12 & 12 & 12 & 12 & 12 & 12 \\
\hline 6 & Isopropyl Alcohol & q.s. & q.s. & q.s. & q.s. & q.s. & q.s. \\
\hline 7 & HPMC K15M & 30 & 35 & 37.5 & 40 & - & - \\
\hline 7A & HPMC K100M & - & - & - & - & 27.5 & - \\
\hline 8 & Carbopol 71G & 5 & 15 & 15 & 15 & 12.5 & 15 \\
\hline 9 & Magnesium Stearate & 2.5 & 2.5 & 2.5 & 2.5 & 2.5 & 2.5 \\
\hline & Layer Weight & 177.5 & 177.5 & 177.5 & 177.5 & 177.5 & 177.5 \\
\hline \multicolumn{8}{|c|}{ Hydrochlorothiazide part (immediate release) } \\
\hline 1 & Hydrochlorothiazide & 12.5 & 12.5 & 12.5 & 12.5 & 12.5 & 12.5 \\
\hline 2 & Lactose monohydrate IP & 40 & 40 & 36.3 & 36.3 & 36.3 & 36.3 \\
\hline 3 & Dibasic calcium phosphate (Anhydrous) & 10.2 & 17 & 27.45 & 27.45 & 27.45 & 27.45 \\
\hline 4 & Starch purity 21 & 25.5 & 21 & 18.5 & 18.5 & 18.5 & 18.5 \\
\hline 5 & Pre-gelatinized starch & 10.5 & 8.2 & 5 & 5 & 5 & 5 \\
\hline 6 & Sodium starch glycolate & 2.5 & 2.5 & 2 & 2 & 2 & 2 \\
\hline 7 & Brilliant blue & 0.3 & 0.3 & 0.25 & 0.25 & 0.25 & 0.25 \\
\hline 8 & Purified water & q.s. & q.s. & q.s. & q.s. & q.s. & q.s. \\
\hline 9 & Sodium starch glycolate & 2.5 & 2.5 & 2 & 2 & 2 & 2 \\
\hline \multirow[t]{3}{*}{10} & Magnesium stearate & 1 & 1 & 1 & 1 & 1 & 1 \\
\hline & Layer weight & 105 & 105 & 105 & 105 & 105 & 105 \\
\hline & Total Tablet Weight & 282.5 & 282.5 & 282.5 & 282.5 & 282.5 & 282.5 \\
\hline
\end{tabular}

\section{Preparation of bilayer tablet}

Both Drugs MPL and HCTZ lubricated powder blend were compressed to prepare tablets on the 11 station rotary Bilayer tablet compression machine using $9.5 \mathrm{~mm}$ round standard convex punches plain on both sides. These prepared tablets were used for further evaluation.

\section{Evaluation of bilayer tablets}

Evaluation of pre-compression parameter8

\section{Total moisture content}

The weighed amount of powder $(1 \mathrm{~g})$ was placed on the IR balance of LOD apparatus METTLER TOLEDO HG-63 Halogen at $105^{\circ} \mathrm{C}$ and the amount of moisture in the granules was determined. 
Acceptance Criteria: the LOD of the granules should be between $2-3 \%$.

\section{Bulk density}

Accurately weighed the quantity of dried granules into graduated $100 \mathrm{ml}$ measuring cylinder, volume was noted and Bulk Density was calculated by given formula.

Bulk Density = Weight of the untapped powder / Volume of the untapped powder

\section{Tapped density}

It was determined by placing a graduated $100 \mathrm{ml}$ measuring cylinder, containing a known mass of dried granules. The cylinder was allowed to fall under its own weight onto a hard surface from the height of $10 \mathrm{~cm}$ at second interval for 100 taps to obtain the constant volume of powder bed. The final volume was noted and Tapped Density was calculated using the following formula.

\section{Tapped Density $=$ Weight of the tapped powder / Volume of the tapped powder}

\section{Carr's compressibility index}

The flow property of the granules was determined by $\%$ Carr's Index. It was calculated by the following formula.

\section{Carr's Index (\%) = Tapped Density-Bulk Density / Tapped Density $\times 100$}

\section{Hausner's ratio}

Hausner's Ration is an indication of flowability of the granules. It was calculated by following formula.

\section{Hausner's Ratio $=$ Tapped Density $/$ Bulk Density}

\section{Sieve analysis}

Sieve Analysis was used to determine the Particle size of granules. The procedure was same as per Particle size determination of API mentioned in Chapter 6.2.1.F.

\section{Evaluation of post-compression parameters ${ }^{9}$}

\section{In-process quality control test}

\section{Weight variation}

Twenty tablets were selected randomly from the lot and weighed individually to check for weight variation. The average weight of tablets was determined and compared with average weight the positive and negative deviation. The tablets meet USP specification if no more than 2 tablets are outside the percentage limit and if no tablets differ by more than 2 than the percentage limit.

\section{Thickness}

Thickness of tablet is important for uniformity of tablets size. Thickness was measured using Digital Vernier Caliper. Thickness of the tablet was checked after compression.

\section{Hardness}

The resistance of tablets to shipping or breakage, under conditions of storage, transportation, and handling before usage, depends on its hardness. The Hardness of the prepared tablets of each formulation was determined using a PHARMA TEST (PTB-411) hardness tester. Ten tablets were tested for hardness from hardness from each batch and mean and SD was calculated. It was measured in terms of Kp.

\section{Friability}

Friability is the measurement of tablet strength. (EF-2) ELECTROLAB friability tester was used for testing the friability. $6.5 \mathrm{~g}$ tablets were weighed accurately and placed in the friabilator that revolves at $25 \mathrm{rpm}$ for 4 min dropping the tablets through a distance of six inches with each revolution. After 100 revolutions the tablets were removed and dedusted, reweighed, and the $\mathrm{p}$

\section{Disintegration time}

In-vitro disintegration time of the prepared tablets was carried out at $\left(37 \pm 2^{\circ} \mathrm{C}\right)$ in $900 \mathrm{ml}$ distilled water using a disintegration test apparatus (Electrolab-ED-2L). 6 tablets were selected randomly and placed in each basket, and the machine was started. The time at which complete tablet get disintegrated was recorded as disintegration time of the tablet.

\section{In-vitro drug release (dissolution) study 10,11,12}

In-vitro drug release studies of all the formulations were carried out using tablets dissolution test apparatus (USP type-II) at $75 \mathrm{rpm}$. Phosphate buffer $900 \mathrm{ml}$, pH 6.8 was used as the dissolution media with the temperature maintained at $\left(37 \pm 0.5^{\circ} \mathrm{C}\right)$. Samples $(5 \mathrm{ml})$ were withdrawn at $60 \mathrm{~min}$, filtered, diluted suitably and analyzed.

Comparative In-vitro release profile with competitor formulation

In-vitro Release Profile study were carried out by using dissolution test apparatus. Comparative drug release profile between competitor formulation (METPURE-H) was carried out by calculating its sililarity factors $\mathrm{f}_{1}$ and $\mathrm{f}_{2}$.

\section{Stability study 13}

The purpose of the testing is to provide evidence on how the quality of a drug substance or drug product varies with time under the influence of a variety of environmental factors such as temperature, humidity, and light, enabling recommended storage conditions, retest periods and shelflives. The International Conference on Harmonization (ICH) Guidelines titled "Stability Testing of New Drug Products" (QIC) describes the stability test requirements for drug registration applications in the European Union, Japan and the United States of America. ICH specifies the length of study and storage conditions.

Accelerated Testing: $40 \pm 2^{\circ} \mathrm{C} / 75 \pm 5 \% \mathrm{RH}$ for 6 months

Intermediate Testing: $30 \pm 2{ }^{\circ} \mathrm{C} / 65 \pm 5 \%$ RH for 6 months

Long-term Testing: $25 \pm 2 \stackrel{\circ}{\circ} / 60 \pm 5 \%$ RH for 12 months

\section{Result and Discussion}

\section{Preliminary studies}

The Preliminary study of both drugs was carried out for different parameters and results are shown in table 2. 
Table 2: Preliminary study of MPL and HCTZ

\begin{tabular}{|c|c|c|c|}
\hline \multirow[t]{2}{*}{ Sr. No. } & \multirow[t]{2}{*}{ Tests } & \multicolumn{2}{|c|}{ Results } \\
\hline & & MPL & HCTZ \\
\hline 1. & Description & White to off-White powder & $\begin{array}{l}\text { White or almost white, odorless, crystalline } \\
\text { powder }\end{array}$ \\
\hline 2. & Solubility & $\begin{array}{l}\text { Freely soluble in water; soluble in } \\
\text { methanol; sparingly soluble in alcohol; } \\
\text { Slightly soluble in isopropyl alcohol. }\end{array}$ & $\begin{array}{l}\text { Soluble in acetone; sparingly soluble in } \\
\text { ethanol (95\%); very slightly soluble in } \\
\text { water; it dissolves in dilute solutions of } \\
\text { alkali hydroxides. }\end{array}$ \\
\hline 3. & Identification By IR & $\begin{array}{l}\text { The IR spectrum of sample should be } \\
\text { concordant with the spectrum obtained } \\
\text { from working standard }\end{array}$ & $\begin{array}{l}\text { The IR spectrum of sample should be } \\
\text { concordant with that of standard spectrum. }\end{array}$ \\
\hline 4. & Loss on Drying & NMT $0.06 \% \mathrm{w} / \mathrm{w}$ & $0.20 \%$ \\
\hline 5. & $\begin{array}{l}\text { Related substances } \\
\text { (By TLC) }\end{array}$ & Less than $0.2 \%$ & Less than $0.50 \%$ \\
\hline 6. & Assay (By HPLC) & 98.9\% (on dried basis) & $99.7 \%$ \\
\hline
\end{tabular}

Evaluation of pre-compression and post-compression parameters

Evaluation of both blends and finished product were carried out by using different methods and results obtained were shown in table 3- table 6. The obtained results were complies with the official pharmacopoeia.

Table 3: Evaluation of pre-compression and post-compression parameters of batch 1-3

\begin{tabular}{|c|c|c|c|c|c|c|c|}
\hline \multirow{2}{*}{$\begin{array}{l}\text { Sr. } \\
\text { No. }\end{array}$} & \multirow{2}{*}{ Parameter } & \multicolumn{2}{|c|}{ B1 } & \multicolumn{2}{|c|}{ B2 } & \multicolumn{2}{|c|}{ B3 } \\
\hline & & MPL & HCTZ & MPL & HCTZ & MPL & HCTZ \\
\hline \multicolumn{8}{|c|}{ In Process Evaluation } \\
\hline 1 & Unlubricated LOD \% w/w & 2.43 & 2.13 & 2.70 & 2.31 & 3.75 & 2.20 \\
\hline 2 & Lubricated LOD \% w/w & 2.72 & 2.47 & 3.26 & 2.45 & 4.27 & 2.35 \\
\hline 3 & Tapped density & 0.555 & 0.714 & 0.560 & 0.704 & 0.540 & 0.720 \\
\hline 4 & Bulk density & 0.425 & 0.625 & 0.432 & 0.595 & 0.410 & 0.616 \\
\hline 5 & Compressibility Index & 23.42 & 12.46 & $21.65 \%$ & $17 \%$ & $25 \%$ & $17.1 \%$ \\
\hline 6 & Hausner's ratio & 1.30 & 1.14 & 1.23 & 1.20 & 1.35 & 1.21 \\
\hline 7 & \% Fines through 60\# & $61.0 \%$ & $69.9 \%$ & $63 \%$ & $56.2 \%$ & $57.5 \%$ & $47.7 \%$ \\
\hline \multicolumn{8}{|c|}{ Finished Product Evaluation } \\
\hline 1 & Tablet dimension (9.5 mm round) & \multicolumn{2}{|c|}{ Complies } & \multicolumn{2}{|c|}{ Complies } & \multicolumn{2}{|c|}{ Complies } \\
\hline 2 & Average weight & \multicolumn{2}{|c|}{$283.90 \mathrm{mg}$} & \multicolumn{2}{|c|}{$283.2 \mathrm{mg}$} & \multicolumn{2}{|c|}{$283.0 \mathrm{mg}$} \\
\hline 3 & Thickness & \multicolumn{2}{|c|}{$3.70-4.32 \mathrm{~mm}$} & \multicolumn{2}{|c|}{$3.75-3.80 \mathrm{~mm}$} & \multicolumn{2}{|c|}{$3.85-4.02 \mathrm{~mm}$} \\
\hline 4 & Hardness & \multicolumn{2}{|c|}{$70-90 \mathrm{~N}$} & \multicolumn{2}{|c|}{$60-80 \mathrm{~N}$} & \multicolumn{2}{|c|}{$50-80 \mathrm{~N}$} \\
\hline 5 & Friability & \multicolumn{2}{|c|}{$0.28 \%$} & \multicolumn{2}{|c|}{$0.21 \%$} & \multicolumn{2}{|c|}{$0.38 \%$} \\
\hline 6 & $\begin{array}{l}\text { Disintegration time (For immediate } \\
\text { release part only) }\end{array}$ & \multicolumn{2}{|c|}{$7: 38 \mathrm{~min}$} & \multicolumn{2}{|c|}{ 6:01 min } & \multicolumn{2}{|c|}{ 8:01 min } \\
\hline 7 & Assay & 103.5 & 98.9 & 93.1 & 101.9 & 104.9 & 93.9 \\
\hline
\end{tabular}


Table 4: In vitro release study of Batch 1-3

\begin{tabular}{|c|c|c|c|c|}
\hline \multicolumn{5}{|c|}{ Dissolution Profile (\% Drug Release) } \\
\hline \multicolumn{5}{|c|}{ Metoprolol } \\
\hline Time (Hr) & Competitor & B1 & B2 & B3 \\
\hline $\mathbf{1}$ & 18 & 38 & 24 & 21 \\
\hline $\mathbf{4}$ & 35 & 79 & 56 & 51 \\
\hline $\mathbf{8}$ & 54 & 105 & 77 & 69 \\
\hline $\mathbf{2 0}$ & 96 & 107 & 104 & 101 \\
\hline $\mathbf{1}$ & 90 & Hydrochlorothiazide & 87 & 89 \\
\hline
\end{tabular}

Table 5: Evaluation of Pre-Compression and Post-Compression Parameters of Batch 4-6

\begin{tabular}{|c|c|c|c|c|c|c|c|}
\hline \multirow{2}{*}{$\begin{array}{l}\text { Sr. } \\
\text { No. }\end{array}$} & \multirow{2}{*}{ Parameter } & \multicolumn{2}{|c|}{ B4 } & \multicolumn{2}{|c|}{ B5 } & \multicolumn{2}{|c|}{ B6 } \\
\hline & & MPL & HCTZ & MPL & HCTZ & MPL & HCTZ \\
\hline \multicolumn{8}{|c|}{ In Process Evaluation } \\
\hline 1 & Unlubricated LOD \% w/w & 2.35 & 2.60 & 2.53 & 2.23 & 2.78 & 1.89 \\
\hline 2 & Lubricated LOD \% w/w & 2.69 & 2.71 & 2.90 & 2.52 & 3.00 & 2.67 \\
\hline 3 & Tapped density & 0.556 & 0.737 & 0.581 & 0.794 & 0.567 & 0.876 \\
\hline 4 & Bulk density & 0.427 & 0.591 & 0.435 & 0.645 & 0.785 & 0.667 \\
\hline 5 & Compressibility Index & $21.73 \%$ & $18.31 \%$ & $24.94 \%$ & $15.15 \%$ & $25.09 \%$ & $17.64 \%$ \\
\hline 6 & Hausner's ratio & 1.23 & 1.20 & 1.24 & 1.06 & 1.23 & 1.12 \\
\hline 7 & $\%$ Fines through $60 \#$ & $61.8 \%$ & $45.0 \%$ & $57.6 \%$ & $40.0 \%$ & $58.57 \%$ & $42.9 \%$ \\
\hline \multicolumn{8}{|c|}{ Finished Product Evaluation } \\
\hline 1 & Tablet dimension (9.5 mm round) & \multicolumn{2}{|c|}{ Complies } & \multicolumn{2}{|c|}{ Complies } & \multicolumn{2}{|c|}{ Complies } \\
\hline 2 & Average weight & \multicolumn{2}{|c|}{$282.9 \mathrm{mg}$} & \multicolumn{2}{|c|}{$283.0 \mathrm{mg}$} & \multicolumn{2}{|c|}{$283.4 \mathrm{mg}$} \\
\hline 3 & Thickness & \multicolumn{2}{|c|}{$3.85-4.00 \mathrm{~mm}$} & \multicolumn{2}{|c|}{$3.91-4.05 \mathrm{~mm}$} & \multicolumn{2}{|c|}{$3.82-3.92 \mathrm{~mm}$} \\
\hline 4 & Hardness & \multicolumn{2}{|c|}{$80-105 \mathrm{~N}$} & \multicolumn{2}{|c|}{$90-110 \mathrm{~N}$} & \multicolumn{2}{|c|}{$85-110 N$} \\
\hline 5 & Friability & \multicolumn{2}{|c|}{$0.19 \%$} & \multicolumn{2}{|c|}{$0.32 \%$} & \multicolumn{2}{|c|}{$0.55 \%$} \\
\hline 6 & $\begin{array}{l}\text { Disintegration time (For immediate } \\
\text { release part only) }\end{array}$ & \multicolumn{2}{|c|}{$6: 53 \mathrm{~min}$} & \multicolumn{2}{|c|}{$7: 41 \mathrm{~min}$} & \multicolumn{2}{|c|}{ 8:09 min } \\
\hline 7 & Assay & 96.8 & 97.0 & 95.5 & 96.3 & 94.44 & 95.98 \\
\hline
\end{tabular}

Table 6: In vitro release study of Batch 4-6

\begin{tabular}{|c|c|c|c|}
\hline \multicolumn{5}{|c|}{ Dissolution Profile (\% Drug Release) } \\
\hline \multicolumn{3}{|c|}{ Metoprolol } \\
\hline Time (Hr) & B4 & 15 & B6 \\
\hline $\mathbf{1}$ & 16 & 34 & 33 \\
\hline $\mathbf{4}$ & 38 & 54 & 53 \\
\hline $\mathbf{8}$ & 64 & 95 & 95 \\
\hline $\mathbf{2 0}$ & 96 & 97 & 94 \\
\hline $\mathbf{1}$ & 91 & Hydrochlorothiazide & \\
\hline
\end{tabular}


Comparative in-vitro release profile with competitor formulation

Comparative drug release profile between competitor formulation (METPURE-H) was carried out by calculating its sililarity factors $f_{1}$ and $f_{2}$. The obtained values of $f_{1}$ and $f_{2}$ were shown in table 7

Table 7: Similarity factor between competitor formulation and optimized batch (B6)

\begin{tabular}{|c|c|}
\hline $\mathrm{f}_{2}$ & 83.56 \\
\hline $\mathrm{f}_{1}$ & 3.45 \\
\hline
\end{tabular}

Values of $\mathrm{f} 1(<15)$ and $\mathrm{f} 2(>50)$ indicate, that the curves can be considered similar. Number of point consideration is based on the guidance of the FDA. From the above results batch no. 6 formula can be considered similar with competitor formula.

\section{Pharmacokinetic modeling of optimized batch}

The data of the optimized formulation was fitted in various pharmacokinetic models. Best fit release kinetic model of batch 6 (B6) is shown in table 8.

Table 8: Regression coefficient values of various pharmacokinetic models

\begin{tabular}{|c|c|c|c|}
\hline Kinetics & Higuchi & Zero & First order \\
\hline Metoprolol Succinate (25 mg) R $\mathbf{~ R}^{2}$ value & 0.9876 & 0.9567 & 0.9789 \\
\hline
\end{tabular}

Drug release kinetics followed Higuchi model as indicated by the $\mathrm{R}^{2}$ value of 0.9876 . Release of drug through polymeric matrices was due to diffusion mechanism.

Higuchi's Square Root of Time Equation (Diffusion model)

$$
\mathbf{Q}=\mathbf{k} \mathbf{t}^{1 / 2}
$$

Where $\mathrm{Q}$ is \% drug release at time $\mathrm{t}$ and $\mathrm{k}$ and $\mathrm{k}$ is a release rate constant
Drug release kinetics followed Higuchi model as indicated by the high value of $\mathrm{R}^{2}$. It indicates that drug release through polymeric matrices was due to diffusion mechanism.

\section{Stability study}

Evaluation of Physicochemical Properties of MPL (Sustained Release Part) and HCTZ (Immediate Release Part) Containing Bilayer Tablet Subjected to Stability studies of optimized batch B6 and the obtained results are shown in table 9.

Table 9: Stability Data of B6 at Accelerated (40 $\left.\pm 2{ }^{\circ} \mathrm{C} \& 75 \pm 5 \% \mathrm{RH}\right)$ Conditions

\begin{tabular}{|c|c|c|c|c|c|}
\hline Test & \multicolumn{2}{|c|}{ Specification } & Initial & 1 month & 2 months \\
\hline Appearance & \multicolumn{2}{|c|}{$\begin{array}{l}\text { A blue/white colored circular, biconvex, } \\
\text { uncoated bilayered tablet. }\end{array}$} & Complies & Complies & Complies \\
\hline Hardness & \multicolumn{2}{|c|}{ NLT $80-110 \mathrm{~N}$} & $90-107 \mathrm{~N}$ & Complies & Complies \\
\hline Friability & \multicolumn{2}{|c|}{ Not more than $1.0 \%$} & $0.31 \%$ & Complies & Complies \\
\hline $\begin{array}{c}\text { Dissolution } \\
\text { (\% Drug Release) }\end{array}$ & Time (Hr) & Competitor & \multicolumn{3}{|c|}{ Batch No 6} \\
\hline \multirow{4}{*}{ Metoprolol } & 1 & 18 & 15 & 14 & 15 \\
\hline & 4 & 35 & 33 & 33 & 32 \\
\hline & 8 & 54 & 53 & 52 & 53 \\
\hline & 20 & 96 & 95 & 95 & 94 \\
\hline Hydrochlorothiazide & 1 & 90 & 94 & 91 & 92 \\
\hline \multirow{2}{*}{ Assay } & \multicolumn{2}{|c|}{ Metoprolol: $90 \%$ - 110\% } & 94.44 & 92.54 & 93.00 \\
\hline & \multicolumn{2}{|c|}{ Hydrochlorothiazide: $90 \%$ - $110 \%$} & 95.98 & 93.45 & 92.00 \\
\hline
\end{tabular}

\section{SUMMARY}

This bilayer tablet dosage form increases the stability which may reduce loss and cost of formulation. It improves the benefits of producer, retailer, and patients. Allergic rhinitis is a common disorder that affects a large population. The treatment goals for Hypertension are relief of symptoms. Therapeutic options available to achieve this goal include various drugs. The combination Metoprolol succinate with hydrochlorothiazide gives additional benefits in comparison with either drug alone and could be considered for patients whose quality of life is impaired by persistent Hypertension.
When tablets of the combination of these are prepared, they tend to become unstable during the shelf life of the formulation. Hence, it is recommended to prepare a bilayer tablet; it improves and increases the stability by reducing the acid-base interactions of both the drugs in combination thereby increasing the bioavailability. To overcome the shortcoming of single-layer tablet approach in this combination like bilayer can be satisfactorily used. In this study demonstrated the successful formulation and evaluation of an Antihypertensive in a single dosage form as a bilayer. 
The parameters like solubility, LOD, IR spectra were evaluated to identify purity of drug and all parameters were found satisfactory and within prescribed official limits. Preformulation study was carried out. One prototype batch, six trial batches and then optimized batch for formulation and development were prepared using wet granulation and compression method. Stability study performed as per ICH guidelines and satisfactory results were obtained which concluded that the batch B6 are supposed to be stable and expected to remain for the period of three years with drugs gives the different release of drug that fixed here in this formulation of both drugs.

\section{CONCLUSION}

The developed formulation of uncoated bilayer tablet using DUREDAS Technology containing combination of antihypertensive drug was similar to standard specification of competitor with all respect and stable to effect of temperature and humidity. There is a lot of future scope for this project. Carrying out technology transfer of the optimized formula by scaling up from lab level to production scale is one of the key challenges. For patent filing, the claimed invention must be nonobvious over the prior art. Here the research work is obvious and DUREDAS technology has also been patented, but the combination of MPL and HCTZ is patentable as no patents have been filed till date on this combination. DUREDAS technology can also be used as platform technology for combination of two or more incompatible drugs, or drugs with different properties and different mechanism of action which provide additive effects in diseases such as diabetes, hypertension, cancer etc. It can be used mainly in case of diseases related to circadian rhythm where a pulsatile release of drug delivery is required.

\section{REFERENCES}

1. Lachman L, Liberman HA. Tablet Dosage Forms, The Theory and Practice of Industrial Pharmacy. $3^{\text {rd }}$ ed, Varghese publishing house; 1987; p.264-269.

2. William CG, Dusel RG. Compression coated and layer tablets, Pharmaceutical Dosage Forms: Tablets. 3rd ed. New York, Basel; 1990; p.273-276.

3. Sowers JR, Epstein M, Frohlich ED. "Diabetes, Hypertension, and Cardiovascular Disease, Hypertension" American Heart Asso. 2007; 37:1053-1059.

4. Tripathi KD. Cardiovascular Drugs. In: Essentials of Medica Pharmacology. $5^{\text {th }}$ ed. Delhi: Jaypee Brothers; 2003; p.503-504.

5. Satoskar RS, Bhandarkar SD, Ainapure SS. Pharmacotherapy of Hypertension. 14th ed. Bombay: Popular Prakashan; 1995; p.358-359.

6. Giles TD, Berk BC, Black HR. "Expanding the definition and classification of Hypertension" American J Clin Hypertension, 2007; 7(9):505-512.

7. DUREDASTM technology. Available at www.elandrugtechnologies.com

8. Q4B Evaluation recommendation of Pharmacopoeial test for use in ICH region general chapter bulk density and tapped density of powders.

9. Nancy JBL, Jackson R. Drugs used in the treatment of Asthma. In: Goodman Gillman A.(Eds.).The pharmacological basis of therapeutics. $10^{\text {th }}$ ed. New york: McGraw Hill: 2001; p.647, 73538.

10. Jahufar S. "Development of Stable Dispersible Bi-layer Tablet of Hydrochlorothiazide and Olmesartan Midoxomil" Int J Pharm Dev. Tech. 2014; 4(4):237-44.

11. United State Pharmacopoeia, 35 NF-30, 2012; (I):5975-77

12. United State Pharmacopoeia, 29 NF-24, 2007; 28: 1061- 62.

13. Q1C ICH guideline for stability testing for new dosage forms. 